\title{
Work Value Orientation and TVET Students' Career Decision-Making Self-Efficacy: The Mediating Role of Academic Major Satisfaction
}

\author{
Azlin Kamaruddin and Roziah Mohd Rasdi* \\ Department of Professional Development and Continuing Education, Faculty of Educational Studies, Universiti \\ Putra Malaysia, 43400 Serdang, Selangor, Malaysia
}

\begin{abstract}
Graduates should know how technical and vocational education and training (TVET) can increase their employability and set them on a path to a professional career. However, graduate underemployment continues to be a severe and rising issue in many countries due to graduates' lack of readiness to make a future career decision. The present study assessed the influence of work value orientation on Career Decision-Making Self-Efficacy (CDMSE) and the mediating role of Academic Major Satisfaction (AMS) on the relationship between work value orientation and CDMSE of TVET students. A cross-sectional survey design was employed, involving 223 full-time Malaysian Skills Certificate (MSC) students who were randomly selected from TVET public institutions in Selangor, Malaysia. This study found that work value orientation was positively correlated with CDMSE. Extrinsic work values have more impact than intrinsic values in serving as precursors to students' career decision-making. Besides, AMS satisfaction mediated the relationship between work value orientation and CDMSE.
\end{abstract}

Keyword: Academic major satisfaction, students, technical and vocational education and training, work value orientation

\begin{tabular}{l} 
ARTICLE INFO \\
\hline Article history: \\
Received: 12 September 2020 \\
Accepted: 09 March 2021 \\
Published: 30 June 2021 \\
\hline DOI: https://doi.org/10.47836/pjssh.29.2.04 \\
\hline E-mail addresses: \\
azlin.kamaruddin82@gmail.com (Azlin Kamaruddin) \\
roziah_m@upm.edu.my (Roziah Mohd Rasdi) \\
*Corresponding author
\end{tabular}

ISSN: 0128-7702

e-ISSN 2231-8534

\section{INTRODUCTION}

TVET has appeared as one of the most important human resource development (HRD) solutions (Afeti \& Stefen, 2014). TVET is a beneficial intervention that can make people more interested in fields of economic activity (Sumberg et al., 2021). TVET can improve student's occupational 
skills and expand their preferences (Aring, 2015). It aims to let learners meet the needs of employers for skilled labor and/ or own needs related to TVET for HRD in the Emerging Knowledge Economy. Because of this, TVET systems have reliable sources of information on job creation, investing avenues, and trade development. As European Training Foundation (2007) alluded TVET generates new jobs and prosperity, it not only builds a competent workforce but stimulates and sustains socioeconomic development.

With noble and ambitious goals, many governments continue to incorporate TVET to address unemployment and poverty alleviation policy gaps. Yet, their goals rarely succeed because TVET remains unattractive among students, resulting in a mismatch of policy goals. Students think that TVET has often been associated with second-class jobs (Lam \& Hassan, 2018). Aziz et al. (2020) highlighted that the view that TVET is a somewhat demeaning option is still held by many students, including those who feel that they need to enroll for it, albeit not as their first choice (Aziz et al., 2020). According to Lauglo (2010), diverting students' perceptions to match their goals with the policy objectives is an important basis for ensuring employability in TVET. In most countries, including Malaysia, there is a TVET mismatch between graduates' talent(s) and labor market demand. Mengistu (2017) particularly stresses that developing nations are unable to achieve their TVET goals if the inherent inconsistency between students' preferences and the education and training they provide is not adequately addressed.

In this respect, Lyngdoh (2005) stated that TVET by itself will not create jobs. Employability is the entirety of TVET and it is determined by numerous factors including the students' career choice. Many researchers verify that most newly enrolled students in TVET across the world often struggle in career choice because choosing an occupation that fits their talents and aspirations is considered a major life decision that highly determines the fate of their future (Yates et al., 2014). Besides, every new student that arrives at training institutions and goes through the process of career choice is usually pre-conditioned by various influences (Watson et al., 2010). Because TVET students' career decisions are a vital aspect of their future success, it is necessary to explore the factors affecting their career decision-making process. To investigate this issue, this study adopted the concept of career decision-making self-efficacy (CDMSE). CDMSE is the belief of a person that he or she will make career choices effectively. Considerable research has reported that individuals with high CDMSE will engage in active career exploration behaviors that lead to a successful career decision (Choi et al., 2012). To investigate further, we focused on variables that influence the CDMSE of TVET students in Malaysia.

According to Pang (2011), the stagnant number in TVET enrolment in Malaysia is an indication that TVET is not a chosen mainstream alternative for school students. 
TVET is considered as a less prestigious study option owing to the stigma associated with it, i.e., that it suits students with less than average academic capabilities (Naziz, 2019). TVET's social stigma was also created by the impression that its primary goal is to appeal to school dropouts rather than equipping students with suitable livelihood qualifications (Ismail \& Hassan, 2013). The struggle with negative stigma has never been easy for TVET students and collectively, all the above indirectly affect the career decision-making self-efficacy of students who opt for TVET to continue their studies.

Like most students, those with TVET backgrounds have different work value orientations (WVOs) from one to another. Students with intrinsic work value orientation tend to have more self-esteem and are expected to have job satisfaction compared with students with extrinsic WVO who prioritize high earnings and other material perks when job-hunting (Brown, 2002). Earning is always a crucial factor in individuals' career choice decisionmaking. According to the life-cycle model, if students hold costs and non-monetary benefits constant, they will be inclined towards choosing a major that offers the best estimate of one's economic future (Berger, 1988). Studies often suggest that students with low CDMSE levels mostly select their profession based on the wage available, without considering career compatibility with their talents, preferences, or skills (Kniveton, 2004; Wang \& Castañeda-Sound, 2008).
The student's sense of fulfillment emerges as an important variable in the learning or education process. The existing TVET scheme is enforced by numerous public and private ministries, departments, and associations, resulting in a plethora of certifications, guidelines, and curricula. This situation has led to difficulty in the standardization of training, qualification, and quality assurance of TVET graduates. According to Ismail and Hassan (2013), TVET-based qualifications are still poorly perceived and not accorded due to low recognition in the workplace.

While Sharf (2010) found that financial considerations (salary, benefits, and incentives) were very important in career decision-making, many other studies that examine diverse aspects in CDMSE among students have yielded findings that are not quite like one another (e.g., Cimsir, 2019; Penn \& Lent, 2019; Willner et al., 2015). Despite voluminous studies on this topic, very few have discussed CDMSE in the context of TVET students. Thus, to bridge the gap in the literature, this study examined the influence of intrinsic and extrinsic WVOs on TVET students' CDMSE and the mediating role of academic major satisfaction (AMS) on this relationship. The findings of the study would be helpful to facilitators and career counselors in planning effective career-related activities, particularly among TVET students.

In the next section, we discuss the theoretical foundations of the study, followed by a conceptual model, and a discussion on hypotheses development. 
Then, the section describes the methods employed and presents the findings of the study. Finally, the researchers discuss limitations and findings implications, as well as highlight gaps for future research.

\section{Theorizing Career Decision-Making Self-Efficacy of TVET Students}

To explore the variable's relationships, this study applied the social cognitive career theory (SCCT). The theory, which was developed by Bandura (1986) is still widely used when variables associated with the career are conceptualized and examined (Swanson \& Gore, 2000). From the SCCT viewpoint, career decision self-efficacy is part of career development and is considered a crucial component of the individual's career interests, goals, choices, experiences, and performance (Jo et al., 2016). The theory explains how cognitive and motivational values, as well as environmental factors, influence career decision-making and career performance (Mohd Rasdi \& Ahrari, 2020).

SCCT postulates that the primary sources of information obtained from learning experiences (i.e. personal experience, vicarious learning, social persuasion, and psychological state of mind) would shape the individual's values, beliefs, and attitudes and would influence his intrinsic and extrinsic work values when he joins the workforce (Johnson \& Elder Jr, 2002). In the context of TVET students, such learning experiences can also be acquired through exposure to prospective careers, information obtained from a variety of sources, and support from significant others.
The SCCT states that an individual's inputs and background context influence his or her learning experiences which are sources of self-efficacy and outcome expectations. It is believed that students' fulfillment of their academic major forms part of their learning experience that will enhance their confidence in making career decisions. Elliott (2002) is of the view that student-centeredness determines how satisfied they are with their overall learning experience. SCCT posits that career interests turn into goals when students have a strong learning experience and environmental support concerning their preferred career paths. In the context of TVET students, academic major satisfaction (AMS) can be acquired from the student's satisfaction with the role played by TVET institutions in developing and nurturing talents as well as proactively promoting and developing a curriculum that matches the expectations and requirements of various industries. Collectively, all these sources influence TVET students' career decision-making self-efficacy.

\section{RELATIONSHIP BETWEEN WVOS AND CDMSE AND THE MEDIATION EFFECT OF ACADEMIC MAJOR SATISFACTION}

\section{Intrinsic and Extrinsic WVOs and CDMSE}

The principles of the intrinsic dimension of work values are the intangibles of having a career, such as pride, involvement in work, and a desire to be committed (Maloni et al., 2017). Meanwhile, the dimension of 
the extrinsic value of work has generally been defined as the attitude towards the social status of a particular job. It relates to the tangible rewards derived from one's career and working environment, such as job security, and material benefits (Ros et al., 1999). A study conducted by Vansteenkiste et al. (2007) indicated that intrinsic WVO is self-actualization and self-expression driven.

In this study, intrinsic WVO concerns TVET students' perceptions of their future employment as opportunities to make use of their competencies and skills, and as such, they become more confident in making career decisions. On the other hand, students with extrinsic WVO view their future jobs as opportunities to acquire financial security and material assets; their career goals include achieving financial success, recruitment by highly ranked organizations, ability to manage and influence others, and holding prestigious positions at work (Vansteenkiste et al., 2007).

Lent et al. (1994) stated that an individual's career choice process consists of numerous cognitive mechanisms, and this is where his or her value orientations play an essential role. Researchers have highlighted the fact that through self-assessment, an individual's value orientations are established and nurtured from the experiences of learning foundational social rules (Lent et al., 2007). There is a potential that it can influence the psychological states, for example, the CDMSE of individuals, when decisions regarding career directions need to be made (Jiang, 2014). Many studies have reported that work value has a significant influence on CDMSE. Regarding the WVOs of students, Doo and Park (2019) investigated the effect of the intrinsic and extrinsic work values of 217 South Korean undergraduates on CDMSE. The research results indicated that intrinsic WVO influenced CDMSE. Abessolo et al. (2017) also suggested that motivated individuals may be driven by such work values and use them as criteria to define their future careers. Hirschi's (2010) longitudinal study found that intrinsic work values were correlated to positive career development. Meanwhile, Gokuladas's (2010) study found that engineering undergraduates students were more confident in making career decisions due to intrinsic work values.

On the other hand, extrinsic work values are a reflection of self-preservation; securing jobs and income is a means to provide basic needs, general security, and orderliness in their lives (Ros et al., 1999). According to Masternak and Ross (1992), extrinsic WVO (i.e., focusing on pay and advancement) is an important factor in assessing job attractiveness, indirectly influencing CDMSE. In contrast, Doo and Park (2019) found an insignificant relationship between extrinsic WVO and CDMSE. Several studies have found that extrinsic work values are more stable than intrinsic work values in terms of the stability of work value types (Easterlin \& Crimmins, 1991; Jin \& Rounds, 2012). Work values of individuals could change from personal selffulfillment to materialism, which reflects extrinsic orientation. Based on the mixed 
findings from past studies, we, therefore, hypothesize that:

$\mathrm{H}_{1}$. Intrinsic WVO influences CDMSE. $\mathrm{H}_{2}$. Extrinsic WVO influences CDMSE.

\section{The Mediation Effect of Academic Major Satisfaction}

Lent et al. (2007) define academic major satisfaction (AMS) as a student's enjoyment of his or her role or experience being a student. Recent descriptions of student populations include the following increased diversity: (i) ethnic identity, (ii) how academically prepared the students were, and (iii) why they choose to attend college (Noel-Levitz Inc, 2005). Sovet et al. (2015) found that AMS was correlated to life satisfaction among college students. In another study, AMS was associated with positive outcomes among students' current and future outcomes (Schenkenfelder, 2017). This follows that when students feel gratified with their selected major and gain confidence from good academic results, they are less likely to drop out (Nauta, 2007).

In this research, AMS is defined as how well students do in their academic major, and how their satisfaction translates into confidence in choosing a suitable career. According to Nauta (2007), AMS is a satisfaction construct that is determined by a student's choice of major. This construct has demonstrated key implications for CDMSE (Jadidian \& Duffy, 2012; Nauta, 2007). Students who believe that their academic pursuits will provide better employment opportunities and satisfying careers are more likely to persist in their studies
(Peterson \& Delmas, 2001). According to Holland (1997), individuals seek similarity with their surroundings. Thus, they actively seek jobs or education programs that closely match their interests. Similarly, students tend to opt for majors that are more related to their interests and characteristics, and those who select satisfying majors are more efficacious in making career decisions (Jurgens, 2000). All these studies have found that WVOs are related to students' satisfaction with their major. Studies by Doo and Park (2019) and Park (2017) showed that intrinsic WVO significantly influenced AMS while extrinsic WVO was found to have little influence on AMS (Doo \& Park, 2019). Choosing a major and engaging in the tasks demanded of that major constitute the process of shaping one's career path. Fouad et al. (2009) and Komarraju et al. (2014) found that AMS was correlated to career decision-making self-efficacy. Choosing a major that is aligned with their interests and abilities helps students to be more self-assured in decisions about their future careers. In other words, they are effectively planning their career path, selecting options that are relevant to their goals, and are determined to overcome frustrations and barriers they may encounter in pursuing their studies.

Based on the above discussion, many studies found that AMS is related to WVOs and CDMSE, while only one study has examined AMS as a mediator between the two variables (Doo \& Park, 2019). The variables of CDMSE and AMS are considered as student outcomes due to their 
impact on the career development of TVET students. CDMSE reflects one's confidence when performing decision-making tasks related to his or her future career paths, a process that TVET students inevitably walkthrough. AMS has been annotated as a student's level of academic satisfaction in terms of class and major options. Allen (1996) further extended that the AMS construct is similar to job satisfaction. Correspondingly, academic environments are comparable to work environments, as both offer individuals opportunities to apply and nurture a sense of self, to develop and hone skills and interests, and to undergo reinforcement patterns. AMS is also expected to influence students' career decisions because it represents their experiences and satisfaction as a student (Sovet et al., 2015). After examining the TVET student population and perceiving that AMS is expected to be an important factor that can explain TVET students' career decision-making, we chose to examine AMS as a mediator. As found by Kim et al. (2019), AMS partially mediated the relationship between academic selfefficacy and academic achievement among nursing students. Studies on the relationship between WVOs and CDMSE among Malaysian TVET students where AMS is examined and tested as a mediator is lacking and have yet to emerge. Based on the above, we hypothesize that:

$\mathrm{H}_{3}$. AMS mediates the relationship between intrinsic WVO and CDMSE. $\mathrm{H}_{4}$. AMS mediates the relationship between extrinsic WVO and CDMSE.

\section{METHODS}

\section{Sampling and Procedures}

A cross-sectional survey design was used in this research. The sample consisted of fulltime students studying for the Malaysian Skills Certificate (MSC) in TVET public institutions in Selangor, Malaysia. Three out of six institutions in Selangor were randomly selected using cluster random sampling. To select the samples of this study, again cluster random sampling was employed to select the classes which were involved in the study. There were 18 classes $(\mathrm{N}=1536)$ that accommodated the samples of the study which comprise students from Level 3 MSC, Level 4 Malaysian Skills Diploma, and Level 5 Malaysian Advanced Skills Diploma students. A total of nine classes were selected randomly using the Fishbowl technique. The technique is practical to be used to randomize a small number of groups/ clusters and it is a very popular method of drawing a random sample. This method also is free from personal bias as every sample has an equal chance to be selected (Miller \& Benz, 2008). The samples were selected based on these criteria: (a) students at Levels 3 to 5 who are considered skilled workers in need by the country as categorized by the Department of Skills Development (DSD) (Levels 1 and 2 were excluded because they are categorized as semi-skilled); (b) at the pre-service stage who were expected to complete their training towards a certificate or diploma qualification; (c) aged 18 years or older, and (d) learners who had chosen their specialization for vocational routes within their respective fields. 
Data were collected using an online survey. Upon permission by the institutions, researchers were then in contact with the nine class instructors and shared the survey link to be distributed to all students in the class. Very few instructors allocated a special slot for the students to answer the online survey form, and mostly, students were asked to answer the survey form after finishing their classes. For the latter group, the duration of one week time was stressed out to them to complete the online questionnaire. It should be noted that most of the students owned a smart mobile phone, thus assuming that this would facilitate online data collection. Nevertheless, only $36.14 \%$ answered the online questionnaire despite several measures such as follow-up calls to the instructors taken to increase the response rate. We received all complete responses because the online survey does not permit incomplete submission.

A total of 223 participants were selected for this study; there were 119 male students (53.4\%) and 104 females (46.6\%). More than $50 \%$ of the respondents were aged between 21-25 years and were at Level 3 (69.5\%), Level 4 (23.8\%), and Level 5 $(6.7 \%)$. A total of $87 \%$ of the students had already set their career goals. Besides, $79.4 \%$ of the participants indicated that their majors matched their future job expectations. However, a total of $3.1 \%$ replied that their majors did not match, and $17.5 \%$ stated that they did not know whether their academic majors matched.

\section{Instrumentation}

The questionnaire consisted of 41 items that were designed to identify intrinsic WVO, extrinsic WVO, AMS, and CDMSE of the respondents, i.e. TVET students. The instruments were content validated by two senior instructors from the institutions who have more than 15 years of experience in teaching TVET students. On top of that, an expert in HRD was appointed to content validate the instruments. The results from all assessments concluded that all instruments were measuring the constructs that they were supposed to measure.

The self-administered online questionnaire took about 15 minutes to be completed in the classrooms and was facilitated by the students' instructors. The respondents were assured of anonymity and confidentiality. A pilot study found that the instrument was reliable, with Cronbach alpha for the scales ranging from $(\alpha=.77$ to $\alpha=.94$ ). The instrument was also checked for content validity by a panel of experts; all the items were found to have measured the constructs of the study satisfactorily.

Career decision-making self-efficacy (CDMSE) items were developed by Taylor and Betz (1983) as a tool to help students understand their career decision and facilitate their career decision-making. This study employed the shorter version of the scale with 25 items, and it was considered to have higher reliability compared to the original scale by Betz and Luzzo (1996). It consisted of items that evaluated self-appraisal, gathering occupational information, goal selection, making plans for a future career, 
and career problem-solving. It was reported that the internal consistency of CDMSE ranged from .73 to .83 for all the 25 items, with the reported Cronbach alpha of .94 . Sample item: "Choose a major or career that will fit your interests". The response options ranged from 1 ('no confidence at all) to 5 ('complete confidence'). The reported internal reliability coefficient in this study was .94 .

Intrinsic and extrinsic WVOs were evaluated by the shorter version of the Work Preference Inventory (WPI) by Robinson et al. (2014). Although the WPI was used to gather responses about the work motivation among physician-scientists, the scale is applicable for the students and the general population (Cheng, 2019; Hayat et al., 2018). Exploratory and confirmatory factor analyses were conducted to reduce the 30 items of WPI as developed by Amabile et al. (1995); the Cronbach alpha $(\alpha)$ for each of the four sub-factors (i.e. challenge and enjoyment as sub-factors of intrinsic motivation; compensation and outward orientation as sub-factors of extrinsic motivation) ranged from .68 to .76. Items were rated on a 4-point Likert scale and ranged from fully disagree (1) to fully agree (4). A sample item for extrinsic WVO: "I am strongly motivated by the recognition I can earn from other people". A sample item for intrinsic WVO: "The more difficult the problem, the more I enjoy trying to solve it". The reported internal reliability coefficient in this study was .74 for extrinsic WVO and .77 for intrinsic WVO.
The academic major satisfaction scale with six items, developed by Nauta (2007), is a uni-dimensional scale consisting of six Likert-like ratings from 1 (strongly disagree) to 6 (strongly agree), where a higher score indicated greater satisfaction with the academic major. Sample item: "I feel good about the major I have selected." The reported reliability for this study was .82 .

\section{RESULTS AND ANALYSIS}

\section{Findings}

This study examined the influence of intrinsic and extrinsic WVOs of TVET students on CDMSE, and the mediating role of AMS in this relationship. Before analysis, the data were tested for normality and linearity and were found to be normally distributed; the residuals were checked for correct applications of statistical analysis. The results indicated that the data for the constructs met all prerequisite assumptions for parametric analyses such as Pearson Product Moment Correlation Coefficient and Multiple Linear Regression. Skewness and kurtosis ranged between -1 and +1 , indicating data normality was satisfied (Georg \& Mallery, 2010).

Table 1 shows the means, standard deviations $(S D)$, and Pearson's intercorrelations of the individual constructs employed in this study. The descriptive statistics showed the following for extrinsic WVO $(\mathrm{M}=3.41 ; S D=0.42)$, intrinsic WVO $(\mathrm{M}=3.24 ; S D=0.45)$, and AMS $(\mathrm{M}=4.79 ; S D=0.80)$. We found several significant correlations amongst our study 
variables. The results showed that there were positive and moderate correlations between extrinsic WVO and CDMSE ( $\mathrm{r}=0.44$; $\mathrm{p}<.05$ ), and intrinsic WVO was positively and moderately correlated with CDSME $(\mathrm{r}=0.50 ; \mathrm{p}<.05)$; AMS was also positively and moderately associated to CDMSE $(r=0.44 ; p<.05)$. This meant that the higher the WVOs the higher the CDMSE.

Table 2 shows the model summary and coefficients for the model of TVET students' CDMSE. A multiple regression model was calculated to investigate the factors contributing to TVET students' CDMSE. The adjusted R-squared value was used to avoid biased estimation. In this study, the coefficient of determination (Adjusted $\mathrm{R}^{2}=.314$ ) showed that $31.4 \%$ of the proportion of variance in CDMSE could be explained by intrinsic and extrinsic WVOs and AMS. The F-ratio showed that the independent variables were statistically and significantly predicted the dependent variable, $F(3,219)=34.814, p<.005$, thus indicating that the model fitted the data. As shown in Table 2, $\mathrm{H}_{1}$ and $\mathrm{H}_{2}$ were accepted. Coefficient values for all the variables, intrinsic WVO $(\beta=.258$, $\mathrm{p}<.05)$, extrinsic WVO $(\beta=.306, p<.05)$, and AMS $(\beta=.183, \mathrm{p}<.05)$ were statistically significant, indicating that extrinsic WVO was the strongest predictors of TVET students' CDMSE. The Durbin-Watson value was 1.801 , falling between values of 1 and 3, thus supported the assumption of independent residuals.

Table 1

Correlations, means, and SDs of study variables

\begin{tabular}{lccccc}
\hline \multicolumn{1}{c}{ Variables } & Mean & $S D$ & Y & X1 & X2 \\
\hline Y CDMSE & 3.74 & 0.56 & & & \\
X1 Extrinsic WVO & 3.41 & 0.42 & $0.44^{*}$ & & \\
X2 Intrinsic WVO & 3.24 & 0.45 & $0.50^{*}$ & $0.65^{*}$ & \\
X3 AMS & 4.79 & 0.80 & $0.44^{*}$ & $0.33^{*}$ & $0.46^{*}$ \\
\hline
\end{tabular}

Note: CDMSE: Career decision-making self-efficacy, WVO: Work value orientation, and AMS: Academic major satisfaction

* Correlation is significant at the .05 level (2-tailed).

Table 2

Estimates of coefficients for the model of CDMSE

\begin{tabular}{llcc}
\hline Dimension & $\beta$ & $t$ & $p$-value \\
\hline (constant) & .990 & 3.531 & .001 \\
Extrinsic WVO & .306 & 3.180 & .002 \\
Intrinsic WVO & .258 & 2.647 & .009 \\
AMS & .183 & 4.202 & .000 \\
\hline
\end{tabular}

Note: WVO: Work value orientation, AMS: Academic major satisfaction $\mathrm{R}=.568 ; \mathrm{R}^{2}=.323$; Adjusted $\mathrm{R}^{2}=.314$; $\mathrm{F}=34.814 ; \mathrm{p}=.000 ;$ Durbin-Watson=1.801 


\section{Testing for the Mediator}

Hypothesis 3 postulated that AMS mediated the relationship between both work value orientations and CDMSE. The results of the simple mediation analysis of SPSS PROCESS macro (Hayes, 2012) are shown in Table 3.

Table 3 shows that the direct effect of intrinsic WVO on AMS $(b=.458, \mathrm{SE}=$ $0.078, t=5.83, \mathrm{p}<.001$ ) was significant, and the direct effect of AMS on CDMSE was also significant $(\mathrm{b}=.188, \mathrm{SE}=0.04$, $t=4.27, \mathrm{p}<.001)$. The mediation effect (i.e. indirect effect) of academic major satisfaction on the relationship between intrinsic WVO and CDMSE $(\mathrm{a} \times \mathrm{b}=.81 \times$ $.19=.15)$ did not include zero in the $95 \%$ confidence interval $(.057, .256)$, indicating that this indirect effect was significant, based on the 5,000 bootstrap method (Preacher $\&$ Hayes, 2004). Further supporting the mediation effect is that when AMS was added into the analysis as a mediator, the path coefficient between intrinsic WVO and CDMSE became significant c' (direct effect) $=.45, \mathrm{SE}=0.078, t=5.83, \mathrm{p}<.001)$.
Results shows similar findings when the direct effect of extrinsic WVO on AMS and the direct effect of AMS on CDMSE were both found to be significant, ( $b=$ $.4431, \mathrm{SE}=0.08, t=5.15, \mathrm{p}<.001)$ and $(b$ $=.188, \mathrm{SE}=0.04, t=4.27, \mathrm{p}<.0015 .53$, $\mathrm{p}<.001)$. The indirect effect of academic major satisfaction on the relationship between extrinsic WVO and CDMSE (a $\times b=.63 \times .23=.14)$, the value of lowerlevel for confidence interval was entirely above zero (.062 to .249), indicating that the mediation effect was significant, based on the 5,000-bootstrap method (refer Table 3). From these findings, we concluded that AMS mediated the relationships between WVOs, both intrinsic and extrinsic, and CDMSE of TVET students. Hence, $\mathrm{H} 3$ and H4 were accepted. Hence, $10.71 \%$ of the proportion of variance of AMS could be explained by intrinsic and extrinsic WVOs.

\section{DISCUSSION}

This study examined the influence of WVOs on CDMSE and the mediating role of AMS on the relationship between

Table 3

Total, direct, and indirect effects

\begin{tabular}{lccccccccc}
\hline \multirow{2}{*}{ Effect } & \multicolumn{3}{c}{ Direct } & \multicolumn{3}{c}{ Indirect } & \multicolumn{3}{c}{ Total } \\
\cline { 2 - 9 } & $\beta$ & t-value & SE & $\beta$ & t-value & SE & $\beta$ & t-value & SE \\
\hline CDMSE & & & & & & & & & \\
AMS & $.188^{* *}$ & 4.27 & 0.041 & & & & $.183^{* *}$ & 4.202 & 0.042 \\
Extrinsic & $.44^{* *}$ & 5.15 & 0.08 & $.14^{* *}$ & 3.24 & 0.048 & $.58^{* *}$ & 7.29 & 0.0805 \\
WVO & & & & & & & & & \\
Intrinsic & $.45^{* *}$ & 5.83 & 0.078 & $.15^{* *}$ & 3.34 & 0.05 & $.61^{* *}$ & 8.43 & 0.072 \\
WVO & & & & & & & & & \\
\hline
\end{tabular}

Note: CDMSE: Career decision-making self-efficacy, WVO: Work value orientation, and AMS: Academic major satisfaction

$* * * \mathrm{p}<.001, * * \mathrm{p}<.05$ 
WVOs and CDMSE of TVET students. The research findings of this study confirmed the significant influence of both intrinsic and extrinsic WVOs on CDMSE of TVET students in Malaysia, and the existence of the mediation effect of AMS. This evidence is supported by the data from the SEM which shows that WVOs and AMS were significantly contributed to the explanation of the variance in CDMSE. This result is aligned with prior research that suggests WVOs influenced AMS and CDMSE (Doo $\&$ Park, 2019). This result is also supported by other previous research findings that work value and major satisfaction of dental hygiene students have a positive effect on CDMSE (Ji \& Heo, 2019).

This study also found that WVOs, especially extrinsic WVO, influenced CDMSE. The result was supported by earlier studies (Kunasegaran et al., 2016). Extrinsic work values such as salary, job security, location, promotional opportunities, and type of work were significant determinants of self-efficacy in making career decisions. Students high in extrinsic work orientation primarily value remuneration and view work principally to attain attractive income (Demerouti et al., 2012). This study also found extrinsic WVO as the strongest predictor of TVET students' CDMSE. The prospect of having attractive jobs (i.e. good remuneration and as well as guaranteed job security) spurs students to choose a major that would fulfill their career aspirations.

This study also reveals that AMS mediates the relationship between both intrinsic and extrinsic WVOs and CDMSE.
This finding supports previous research about the significant influence of AMS on CDMSE (Doo \& Park, 2019; Jadidian \& Duffy, 2012; Nauta, 2007). Student's workrelated reinforcement preferences seem to be more influenced when they feel satisfied with their performance academically, and consequently, this increases their confidence in making career decisions. These results indicate that what students learn during their course allows them to assess their own needs and skills, to plan their career path effectively, to select choices that are relevant to their goals, and to assess the obstacles they may encounter in the pursuit of their careers. According to Agrawal (2013), TVET prepares individuals for effective performance on psychomotor tasks. TVET environments should be fully equipped with facilities and opportunities that match TVET students' interests. Providing students with a supportive learning environment (i.e. studying a major of their own choice, as well as one that matches their interest) facilitates and reinforces learning, and helps students acquire the requisite technical skills for the career they have opted for. On top of that, expanding the industry network among TVET players helps to open doors to more lucrative jobs for TVET graduates.

\section{LIMITATIONS AND FUTURE STUDIES}

The study has several limitations which offer opportunities for further investigation in future research. First, we employed a cross-sectional survey design and the construct of CDMSE was measured based 
on TVET students' perceptions. This might have limited the understanding of CDMSE among the participants. Future researchers are encouraged to extend this study by investigating CDMSE using qualitative studies. Besides, because a correlational design was employed in this study, causal relationships were not investigated. Thus, future studies could embark on an experimental design to examine causal relationships between the same constructs on students' career decision-making. Although the positioning of the variables in the present study is supported by the literature, more research is required to scrutinize the associations of other pertinent variables such as motivation factors or other internal and external factors to have a better understanding of CDMSE relationships. Besides, future studies could adopt a qualitative paradigm to explore other constructs that would explain associations with students' CDMSE. Finally, the generalization of the research findings to other cultures or countries is limited. Future research could involve participants from diverse backgrounds and technical streams to examine the influence of demographic variables, such as gender, race, and culture on students' career decision-making. Studies focusing on other providers (public and private training institutions) and other streams such as medical, engineering, or other non-technical stream are essential to provide different perspectives on the outcomes of the CDMSE research.

\section{CONCLUSION AND IMPLICATIONS FOR PRACTICE AND THEORY}

In this study, we conclude that WVOs and AMS are functions of TVET students' CDMSE. Both intrinsic and extrinsic work values are precursors to efficacious students' career decision-making, but extrinsic work value is found to have a stronger impact compared to intrinsic work value. Academic satisfaction or subjective evaluation of the whole educational experience explains the interdependence of students' WVOs and their career decision-making self-efficacy.

As pointed out above, extrinsic WVO is found to have a stronger influence on CDMSE than intrinsic WVO. This can be attributed to borderless information that allows students to gain information and forecast their future in the TVET ecosystem. The future for TVET graduates certainly looks brighter, what with the government's efforts to raise TVET certification to a level similar to academic qualifications. Strong collaboration between industries and TVET institutions, attractive remuneration, and opportunities to be absorbed into large organizations with career assurance are some of the strategies to improve the enrolment of students at TVET institutions.

This study also found that AMS mediated the relationship between WVOs and CDMSE. As such, perhaps TVET institutions could administer yearly student satisfaction surveys to measure students' level of satisfaction on the overall knowledge transfer experience. TVET institutions could also make use of diverse internal 
assessment tools such as self-evaluation checklists or psychological inventory scales to better understand the values, skills, personality, and interests of students. Subsequently, continual improvements can be made by TVET institutions to support and facilitate the development of cognitive and psychomotor abilities of their students. This might help to give a better assessment of students' intrinsic and extrinsic work values which lead to their CDMSE. Apart from that, TVET institutions need to scrutinize the process of selection of new intakes to ensure only qualified and enthusiastic individuals are selected. This will smoothen the learning and training process because the courses chosen by students should be aligned with their passion to make their learning experiences more meaningful and satisfying.

This study also suggests optimizing the roles of counselors in gearing students' career interests and choices. Counseling sessions may be necessary to facilitate students' awareness of intrinsic and extrinsic work values. Several methods such as career coaching sessions, as well as mentoring programs, could be implemented with customized approaches to strengthen students' psychomotor abilities. TVET institutions could also conduct sessions for students to interact with professionals in the relevant fields to increase their knowledge and expand the range of career options. This would facilitate their engagement with career preparation activities, and help better equip them with the realities and expectations of the working world.
We also propose that TVET institutions develop programs to help extrinsically work-oriented students who focus on high earnings and attractive perks rather than opportunities for growth at the workplace. TVET institutions are also recommended to synchronize their programs to match the needs of the industry. It is important to expand and strengthen networking with the industries to enjoy various benefits, e.g. financial sponsorship or conducting a dual-track learning approach with classroom training combined with an apprenticeship at a hosting company. Students will be more inspired to explore more, and it will boost their confidence in opting for careers that require TVET certifications.

WVOs and AMS have a significant influence on CDMSE, implying that it is important to conduct a continual needs assessment to enable students to set their WVOs appropriately and build up their confidence in charting their career paths. The assessment exercise would help to highlight students' interest and engagement in the chosen field of study and would indirectly prepare them for employment. Reinforced by a wide range of networks and robust support systems, committed students would be more optimistic, particularly in deciding their future careers.

This study attempts to contribute to the CDMSE theory literature in several ways. First, prior work on the mediating role of CDMSE in SCCT focused on its indirect influence on career-related outcomes ( $\mathrm{Li}$ et al., 2019; Santos et al., 2018). Less research has been devoted to its antecedents. In 
this research, we have demonstrated that extrinsic and intrinsic WVOs among TVET students increase CDMSE. Our results support outcome expectations of SCCT such that career-related outcome expectations may map neatly onto and incorporate work values (Lent et al., 1994). Second, although prior work has examined WVOs and AMS as predictors of CDMSE (Doo \& Park, 2019), the exact nature of their relationship is not well understood in the TVET context. Our results helped clarify the interrelationships between these three constructs which increased our knowledge of how CDMSE among TVET students is cultivated. Indeed, this study proposes that the AMS mediator explains TVET students' career decisions.

\section{ACKNOWLEDGEMENT}

Authors would like to extend our sincere gratitude to the Malaysia Public Service Department (JPA) for the study sponsorship and to the management of TVET Institutions for their participation and cooperation in the data collection process.

\section{REFERENCES}

Abessolo, M., Rossier, J., \& Hirschi, A. (2017). Basic values, career orientations, and career anchors: Empirical investigation of relationships. Frontiers in Psychology, 8, 1556. https://doi. org/10.3389/fpsyg.2017.01556

Afeti, G., \& Stefen, T. (2014). TVET policy review: South Sudan. UNESCO. https://unesdoc.unesco. org/ark:/48223/pf0000231287

Agrawal, P. (2013). Indian experience of internal and international collaboration in TVET and prospects of regional cooperation.TVET@Asia, 1, 1-13.

Allen, M. L. (1996). Dimensions of educational satisfaction and academic achievement among music therapy majors. Journal of Music Therapy, 33(2), 147-160. https://doi.org/10.1093/ jmt/33.2.147

Amabile, T. M., Hil, K. G., Hennessey, B. A., \& Tighe, E. M. (1995). "The Work Preference Inventory: Assessing intrinsic and extrinsic motivational orientations": Correction. Journal of Personality and Social Psychology, 66(5), 950-967. https:// doi.org/10.1037/0022-3514.68.4.580

Aring, M. (2015). ASEAN Economic Community 2015: Enhancing competitiveness and employability through skill development (pp. 1-85). ILO.

Aziz, S. N. B. A., Zulkifli, N., Nashir, I. M., \& Karim, N. A. A. (2020). Pull and push factors of students' enrolment in the TVET programme at community colleges in Malaysia. Journal of Technical Education and Training, 12(1), 68-75.

Bandura, A. (1986). Social foundations of thought and action. Prentice Hall.

Berger, M. C. (1988). Predicted future earnings and choice of college major. ILR Review, 41(3), 418-429. https://doi. org/10.1177/001979398804100306

Betz, N. E., \& Luzzo, D. A. (1996). Decisionmaking self-efficacy scale. Journal of Career Assessment, 4(1), 45-47.

Brown, D. (2002). The role of work and cultural values in occupational choice, satisfaction, and success: A theoretical statement. Journal of Counseling \& Development, 80(1), 48-56.

Cheng, W. (2019). How intrinsic and extrinsic motivations function among college student samples in both Taiwan and the US. Educational Psychology, 39(4), 430-447.

Choi, B. Y., Park, H., Yang, E., Lee, S. K., Lee, Y., \& Lee, S. M. (2012). Understanding career decision 
self-efficacy: A meta-analytic approach. Journal of Career Development, 39(5), 443-460.

Cimsir, E. (2019). Insight, academic major satisfaction and life satisfaction among college students majoring in education: Implications for career counselling. Journal of Psychologists and Counsellors in Schools, 29(2), 206-218.

Demerouti, E., Bakker, A. B., \& Fried, Y. (2012). Work orientations in the job demands-resources model. Journal of Managerial Psychology, 27(6), 557-575.

Doo, M. Y., \& Park, S. H. (2019). Effects of work value orientation and academic major satisfaction on career decision-making self-efficacy. Higher Education, Skills and Work-Based Learning, 9(4), 550-562.

Easterlin, R. A., \& Crimmins, E. M. (1991). Private materialism, personal self-fulfillment, family life, and public interest THE nature, effects, and causes of recent changes in the values of American youth. Public Opinion Quarterly, 55(4), 499-533.

Elliott, K. M. (2002). Key determinants of student satisfaction. Journal of College Student Retention: Research, Theory \& Practice, 4(3), 271-279.

European Training Foundation. (2007). Skills development and poverty reduction: A state of the art review.

https://www.etf.europa.eu/sites/default/files/m/ C12578310056925BC12573AF00520109_ NOTE79TKHJ.pdf

Fouad, N., Cotter, E. W., \& Kantamneni, N. (2009). The effectiveness of a career decision-making course. Journal of Career Assessment, 17(3), 338-347.

Georg, D., \& Mallery, P. (2010). SPSS for windows step by step: A simple guide and references (17th ed.). Allyn and Bacon.
Gokuladas, V. K. (2010). Technical and non-technical education and the employability of engineering graduates: An Indian case study. International Journal of Training and Development, 14(2), 130-143.

Hayat, A. A., Salehi, A., \& Kojuri, J. (2018). Medical student's academic performance: The role of academic emotions and motivation. Journal of Advances in Medical Education \& Professionalism, 6(4), 168-175.

Hayes, A. F. (2012). PROCESS: A versatile computational tool for observed variable mediation, moderation, and conditional process modeling 1 . University of Kansas.

Hirschi, A. (2010). Positive adolescent career development: The role of intrinsic and extrinsic work values. The Career Development Quarterly, 58(3), 276-287.

Holland, J. L. (1997). Making vocational choices: A theory of vocational personalities and work environments (3rd ed.). Psychological Assessment Resources.

Ismail, A., \& Hassan, R. (2013, July 1-2). Issue and challenges of Technical and Vocational Education and Training in Malaysia for knowledge worker driven. National Conferences on Engineering Technology (NCET), Shah Alam, Malaysia.

Jadidian, A., \& Duffy, R. D. (2012). Work volition, career decision self-efficacy, and academic satisfaction: An examination of mediators and moderators. Journal of Career Assessment, 20(2), 154-165.

Ji, J.-H., \& Heo, S.-E. (2019). The effects of work value and major satisfaction of dental hygiene students on career decision self-efficacy. Journal of Convergence for Information Technology, 9(6), 183-193.

Jiang, Z. (2014). Emotional intelligence and career decision-making self-efficacy: National and gender differences. Journal of Employment 
Counselling, 51(3), 112-124. https://doi. org/10.1002/j.2161-1920.2014.00046.x

Jin, J., \& Rounds, J. (2012). Stability and change in work values: A meta-analysis of longitudinal studies. Journal of Vocational Behavior, 80(2), 326-339.

Jo, H., Ra, Y.-A., Lee, J., \& Kim, W. H. (2016). Impact of dysfunctional career thoughts on career decision self-efficacy and vocational identity. The Career Development Quarterly, 64(4), 333-344.

Johnson, M. K., \& Elder Jr, G. H. (2002). Educational pathways and work value trajectories. Sociological Perspectives, 45(2), 113-138.

Jurgens, J. C. (2000). The undecided student: Effects of combining levels of treatment parameters on career certainty, career indecision, and client satisfaction. The Career Development Quarterly, 48(3), 237-250.

Kim, J., Kim, H. O., \& Lee, M. (2019). Academic achievement of nursing college students according to academic self-efficacy: The mediating effect of major satisfaction. Child Health Nursing Research, 25(2), 205-213.

Kniveton, B. H. (2004). The influences and motivations on which students base their choice of career. Research in Education, 72(1), 47-59.

Komarraju, M., Swanson, J., \& Nadler, D. (2014). Increased career self-efficacy predicts college students' motivation, and course and major satisfaction. Journal of Career Assessment, 22(3), 420-432.

Kunasegaran, M., Ismail, M., Rasdi, R. M., Ismail, I. A., \& Ramayah, T. (2016). Talent development environment and workplace adaptation. European Journal of Training and Development, 40(6), 370-389. https://doi.org/10.1108/ejtd-072015-0060

Lam, K. W., \& Hassan, A. (2018). Instructional technology competencies perceived by technical and vocational education and training (TVET) students in Malaysia. International Journal of Academic Research in Business and Social Sciences, 8(5), 343-366.

Lauglo, J. (2010). Revisiting the vocational school fallacy: A tribute to Philip Foster. Comparative Education, 46(2), 223-235.

Lent, R. W., Brown, S. D., \& Hackett, G. (1994). Toward a unifying social cognitive theory of career and academic interest, choice, and performance. Journal of Vocational Behavior, 45(1), 79-122.

Lent, R. W., Singley, D., Sheu, H.-B., Schmidt, J. A., \& Schmidt, L. C. (2007). Relation of social-cognitive factors to academic satisfaction in engineering students. Journal of Career Assessment, 15(1), 87-97.

Li, H., Ngo, H., \& Cheung, F. (2019). Linking protean career orientation and career decidedness: The mediating role of career decision self-efficacy. Journal of Vocational Behavior, 115, 103322.

Lyngdoh, B. W. (2005). Skills for work in the future: A youth perspective. Prospects, 35(3), 311-316.

Maloni, M. J., Campbell, S. M., Gligor, D. M., Scherrer, C. R., \& Boyd, E. M. (2017). Exploring the effects of workforce level on supply chain job satisfaction and industry commitment. The International Journal of Logistics Management, 28(4), 1294-1318.

Masternak, R. L., \& Ross, T. L. (1992). Gainsharing: A bonus plan or employee involvement? Compensation \& Benefits Review, 24(1), 46-54.

Mengistu, M. (2017). Graduate employability as a function of career decision in the Amhara State TVET system. Ethiopian Journal of Education and Sciences, 13(1), 1-21.

Miller, R. L., \& Benz, J. J. (2008). Techniques for encouraging peer collaboration: Online threaded discussion or fishbowl interaction. Journal of Instructional Psychology, 35(1), 87-93. 
Mohd Rasdi, R., \& Ahrari, S. (2020). The applicability of social cognitive career theory in predicting life satisfaction of university students: A metaanalytic path analysis. PLOS One, 15(8), 1-22. https://doi.org/10.1371/journal.pone.0237838

Nauta, M. M. (2007). Assessing college students' satisfaction with their academic majors. Journal of Career Assessment, 15(4), 446-462.

Naziz, A. (2019). Collaboration for transition between TVET and university: A proposal. International Journal of Sustainability in Higher Education, 20(8), 1428-1443.

Noel-Levitz Inc. (2005). How to generate purposeful change on your campus: A realistic approach to institutional assessment. https://files.eric.ed.gov/ fulltext/ED536857.pdf

Pang, C. L. (2011, August 2-3). Key reforms in revitalising Technical and Vocational Education and Training (TVET) in Malaysia. Regional Conference on Human Resource Development Through TVET as a Development Strategy, Colombo, Sri Lanka.

Park, Y. (2017). An analysis on the structural model of college major satisfaction and first job satisfaction: Focusing on the mediating effect of job match and intrinsic job value [Master's thesis]. Korea University.

Penn, L. T., \& Lent, R. W. (2019). The joint roles of career decision self-efficacy and personality traits in the prediction of career decidedness and decisional difficulty. Journal of Career Assessment, 27(3), 457-470. https://doi. org/10.1177/1069072718758296

Peterson, S. L., \& Delmas, R. C. (2001). Effects of career decision-making self-efficacy and degree utility on student persistence: A path analytic study. Journal of College Student Retention: Research, Theory \& Practice, 3(3), 285-299.

Preacher, K. J., \& Hayes, A. F. (2004). SPSS and SAS procedures for estimating indirect effects in simple mediation models. Behavior Research Methods, Instruments, and Computers, 36(4), 717-731.

Robinson, G. F. W. B., Switzer, G. E., Cohen, E. D., Primack, B. A., Kapoor, W. N., Seltzer, D. L., $\&$ Rubio, D. M. G. (2014). Shortening the work preference inventory for use with physician scientists: WPI-10. Clinical and Translational Science, 7(4), 324-328.

Ros, M., Schwartz, S. H., \& Surkiss, S. (1999). Basic individual values, work values, and the meaning of work. International Association of Applied Psychology, 48(1), 49-71.

Santos, A., Wang, W., \& Lewis, J. (2018). Emotional intelligence and career decision-making difficulties: The mediating role of career decision self-efficacy. Journal of Vocational Behavior, 107, 295-309. https://doi.org/10.1016/j. jvb.2018.05.008

Schenkenfelder, M. C. (2017). Predicting academic major satisfaction using environmental factors and self-determination theory [Master's dissertation]. Iowa State University Capstones.

Sharf, R. S. (2010). Applying career development theory to counseling. Brooks/ Cole.

Sovet, L., Tak, J., \& Jung, S. (2015). Validation of the career decision-making difficulties questionnaire among Korean college students. Journal of Career Assessment, 23(4), 661-676. https://doi. org/10.1177/1069072714553556

Sumberg, J., Fox, L., Flynn, J., Mader, P., \& Oosterom, M. (2021). Africa's "youth employment" crisis is actually a "missing jobs" crisis. Development Policy Review, 1-23. https://doi.org/10.1111/ dpr. 12528

Swanson, J. L., \& Gore, P. A. (2000). Advances in vocational psychology theory and research. In S. D. Brown \& R. W. Lent (Eds.), Handbook of counseling psychology (pp. 233-269). John Wiley \& Sons Inc. 
Taylor, K. M., \& Betz, N. E. (1983). Applications of self-efficacy theory to the understanding and treatment of career indecision. Journal of Vocational Behavior, 22(1), 63-81.

Vansteenkiste, M., Neyrinck, B., Niemiec, C. P., Soenens, B., De Witte, H., \& Van Den Broeck, A. (2007). On the relations among work value orientations, psychological need satisfaction and job outcomes: A self-determination theory approach. Journal of Occupational and Organizational Psychology, 80(2), 251-277.

Wang, C.-C. D., \& Castañeda-Sound, C. (2008). The role of generational status, self-esteem, academic self-efficacy, and perceived social support in college students' psychological well-being. Journal of College Counseling, 11(2), 101-118.
Watson, M., McMahon, M., Foxcroft, C., \& Els, C. (2010). Occupational aspirations of low socioeconomic black South African children. Journal of Career Development, 37(4), 717-734.

Willner, T., Gati, I., \& Guan, Y. (2015). Career decision-making profiles and career decisionmaking difficulties: A cross-cultural comparison among US, Israeli, and Chinese samples. Journal of Vocational Behavior, 88, 143-153. https://doi. org/j.jvb.2015.03.007

Yates, A., Brindley-Richards, W., \& Thistoll, T. (2014). Student engagement in distance-based vocational education. Journal of Open, Flexible, and Distance Learning, 18(2), 29-43. 
